\title{
McGinn-White Sign or S1Q3T3-Pattern in Pulmonary Embolism; Significance and Differential Diagnosis; Narrative Updating Review
}

\author{
Yasser Mohammed Hassanain Elsayed* \\ Critical Care Unit, Fraskour Central Hospital, Damietta Health Affairs, Egyptian Ministry of Health \\ (MOH), Damietta, Egypt \\ *Corresponding Author: Yasser Mohammed Hassanain Elsayed, Critical Care Unit, Fraskour \\ Central Hospital, Damietta Health Affairs, Egyptian Ministry of Health (MOH), Damietta, Egypt.
}

\begin{abstract}
Pulmonary embolism is a serious clinical cardiopulmonary event. The blockage of pulmonary vasculature by a substance that has moved from elsewhere in the body via the bloodstream is considered the prescriptive hallmark for pulmonary embolism. An acceleration in its early diagnosis and treatment is an essential step to prevent both morbidity and mortality. Pulmonary embolism has a high fatality rate with an outspread incidence. The annual incidence of pulmonary embolism in Europe is 430,000 cases and the rate is between 500,000 and 600,000 cases in the United States. and results in between 200,000 and 300,000 deaths. An electrocardiograph is an important tool for the diagnosis of pulmonary embolism. McGinn-White sign or S1Q3T3-pattern is a famous ancient electrocardiographic sign that carries wide significant prognostic value regards pulmonary embolism. But, the classic S1Q3T3-pattern is neither pathognomonic, sensitive, nor specific finding. The clinical data is the most important factor for the physician in the directory of the outcome for S1Q3T3-pattern. This is a pivotal step in the narrative updating review of the current sign.
\end{abstract}

Keywords: McGinn-White sign, S1Q3T3-pattern, Pulmonary embolism, Significance and differential diagnosis

\section{ABBREVIATIONS}

ACP: Acute cor-pulmonale

AF: Atrial fibrillation

ECG: Electrocardiograph

ED: Emergency department

LV: Left ventricle

PE: Pulmonary embolism

PHT: Pulmonary hypertension

RA: Right atrial

RAD: Right axis deviation

RBBB; Right bundle branch block

RV: Right ventricular

TR: Tricuspid regurgitation

\section{HistoricAL BIT}

Historically, the initial elucidatory character of electrocardiographic (ECG) abnormalities in pulmonary embolism (PE) was described by both scientists; Sylvester McGinn and Paul White in $1935 .{ }^{1}$ They revealed that a remarkable number of cases shared the recognizable analogous constellation of findings of an Swave (amplitudes of $\geq 1.5 \mathrm{~mm}$ ) in lead I, Q- wave (amplitudes of $\geq 1.5 \mathrm{~mm}$ ) in lead III, and an inverted T-wave in lead III. ${ }^{1,2}$ Indeed, the traditional McGinn-White sign (S1Q3T3) was detected in only one-tenth to one-halve of cases of PE. ${ }^{3,45}$ McGinn and White first described the S1Q3T3-pattern with these subsequent voltage criteria in acute cor-pulmonale (ACP) due to PE: (A). S-wave in lead I. (B). Q-wave in lead III with an amplitude of more than $0.15 \mathrm{mV}$. (C). The inversion of the T-wave in lead III. ${ }^{\mathbf{1 , 5}}$

\section{INTRODUCTION}

Pulmonary embolism is one of the most fatal cardiopulmonary presentations in the emergency department (ED). ${ }^{3}$ The blockage of pulmonary vasculature by a substance that has moved from elsewhere in the body via the bloodstream is considered the prescriptive hallmark for pulmonary embolism. ${ }^{2}$ An acceleration in its early diagnosis and treatment is an essential step to prevent both morbidity and mortality. ${ }^{6,7}$ The annual incidence of pulmonary embolism in Europe is 430,000 cases and the rate is between 500,000 and 600,000 cases in the United States. and results in between 200,000 and 300,000 deaths. ${ }^{8}$ Nearly, yearly 200,000 new cases of 
McGinn-White Sign or S1Q3T3-Pattern in Pulmonary Embolism; Significance and Differential Diagnosis; Narrative Updating Review

venous thromboembolism (VTE) are diagnosed with an approximately six percent 30-day fatality rate from PE. ${ }^{2}$ Pulmonary embolism is a highly prevalent clinical disorder that is mostly carrying under-recognizing, under-diagnosing, and potentially fatal direction. ${ }^{9}$ Clinical findings of $\mathrm{PE}$ is usually having poor diagnostic value in the PE per se. ${ }^{3}$ The symptoms of PE are undependable in the diagnosis of PE. ${ }^{3}$ Nearly, most cases of PE do so within the first few hours of the presentation. ${ }^{9}$ About, $10 \%$ of PE is ending to sudden death in the first hour. Anyhow, PE presents with a wide-clinical spectrum, starting from asymptomatic embolism to fatal shocked massive PE.' However, identifying these ECG signs could help clinicians to earlier diagnosis of the PE. ${ }^{6}$ According to an international registry study (IRS), massive PE was existing in less than 5\% of adult PE but with a $50 \%$ mortality. ${ }^{10,11}$

\section{THE DESCRIPTION OF SIGN}

McGinn and White had innovated the S1Q3T3pattern in 1935 with these subsequent voltage criteria in ACP due to APE: S wave in lead I, Qwave in lead III, and amplitude of more than $0.15 \mathrm{mV}$ with the T-wave inversion in lead III. ${ }^{5}$ The sign is defined as the presence of a Q-wave in lead III, late inversion of the T-wave in lead III, and S-wave in lead I with right QRS axis deviation. ${ }^{4,12}$ Indeed, the classic right ventricular (RV) strain, S1Q3T3-pattern is commonly debated but occasionally visible. ${ }^{13}$ McGinn and White $^{1}$ revealed there are certain aberrations of a constellation of ECG S1Q3T3 signs that include: (A). Prominent S-wave with the low origin of the T-wave in lead I. (B). Gradual staircase ascent of the ST-interval from the Swave to the T wave in lead II. (C). Q-wave and definite late inversion of the T-wave in lead III. Both McGinn and White described ECGpatterns of deep S-wave in lead I, Q-wave in lead III, and inverted T-wave in lead III in patients with RV change due to pulmonary vascular disorders like in RV dilatation, pulmonary hypertension (PHT), and pneumothorax. ${ }^{14,15,16}$

INCIDENCE, CLINICAL IMPORTANCE, AND PROGNOSTIC VALUE

Unfortunately, S1Q3T3-pattern is not detected in all cases of PE. ${ }^{17}$ The incidence of McGinnWhite sign or S1Q3T3-pattern in classic PE is ranged between $10 \%$ to $50 \%$ of cases. ${ }^{2-5,18-23}$ There are wide variations according to the incidence in different studies (Table 1). A minority of patients (12\%) postangiographically documented acute PE, initially, had the ECG S1Q3T3. ${ }^{21}$

Table1. Electrocardiographic S1Q3T3 variation in different studies of pulmonary embolism from 1958 to 1994.

\begin{tabular}{|c|c|c|c|c|c|c|}
\hline No & Study & Year & $\begin{array}{c}\text { No of } \\
\text { patients }\end{array}$ & $\begin{array}{c}\text { Percent of S1Q3T3 Pattern } \\
\text { in PE (\%) }\end{array}$ & Notes & Reference \\
\hline 1. & Cutforth RH al. & 1958 & 50 & 8.33 & \multirow{14}{*}{$\begin{array}{l}\text { Subgroups } \\
\text { according to QS }\end{array}$} & 73 \\
\hline 2. & Marchick MR et al. & 2010 & 6049 & 8.5 & & 70 \\
\hline 3. & Jimenez D et al. & 1970 & 302 & 9.44 & & 74 \\
\hline 4. & Chua JC et al. & 2013 & 100 & 11 & & 75 \\
\hline 5. & Stein PD et al. & 1975 & 90 & 12 & & 55 \\
\hline \multirow[t]{2}{*}{6.} & Rodrigues B et al. & 2012 & 39 & 15.2 if $\mathrm{QS}^{*}<18$ & & 37 \\
\hline & & & 63 & 35.1 if $\mathrm{QS}^{*}>18$ & & \\
\hline 7. & Petruzzelli S et al. & 1986 & 245 & 16 & & 27 \\
\hline 8. & Shopp JD et al. & 2015 & 382 & 24 & & 36 \\
\hline 9. & Calvo-Romero1 et al. & 2005 & 107 & 26.6 & & 12 \\
\hline 10. & Nielsen TT et al. & 1989 & 87 & 44 & & 61 \\
\hline 11. & Ferrari E et al. & 1997 & 80 & 50 & & 57 \\
\hline 12. & Lenègre $\mathrm{J}$ et al. & 1970 & 50 & 52 & & 76 \\
\hline 13. & Sreeram $\mathrm{N}$ et al. & 1994 & 49 & $\mathrm{NR}^{* *}$ & & 20 \\
\hline
\end{tabular}

\section{QQS=Qanadli score ${ }^{* *} N R=$ not reported}

S1Q3T3-pattern is ECG abnormalities harmonious with acute PE. ${ }^{\mathbf{1 2}}$ Although, the S1Q3T3-pattern carries a lack of specificity in the diagnosis of PE. But the pattern is still used diagnostic tool. An identify the S1Q3T3 pattern is very important for clinical practice. ${ }^{24,25}$ It is an acceptable well-known signal for acute PE. ${ }^{17}$ Also, the pattern not sensitive, but it will raise the suspicion of APE. ${ }^{6}$ Thus the presence of this pattern associated with ECG along with clinical findings is highly suspicious of PTE. ${ }^{26}$ McGinnWhite sign are remarkably more frequent in patients with confirmed PE. ${ }^{6,27}$ Despite it is not the commonest ECG finding in PE but the pattern is often taught in ECG classes. ${ }^{28}$ Recognizing the ECG McGinn-White sign could prompt clinicians to consider PE for the earlier right diagnosis. ${ }^{6}$ S1Q3T3 pattern is considered 
McGinn-White Sign or S1Q3T3-Pattern in Pulmonary Embolism; Significance and Differential Diagnosis; Narrative Updating Review

to be more common with massive embolism than with smaller emboli. ${ }^{29}$ Nevertheless, S1Q3T3-pattern has been shown to link with poorer short-term prognosis in acute $\mathrm{PE}^{\mathbf{1 0}}$ S1Q3T3 sign is more frequently seen in patients with complications post APE. $^{\mathbf{3 0}}$ This rare S1Q3T3-pattern have been correlating with poorer outcome in PE. ${ }^{\mathbf{1 1}}$ The presence of the S1Q3T3 is an indicator of RV strain with ACP. ${ }^{4,22,31-34}$ It has been extrapolated that S1Q3T3 is a sign of RV change due to occlusion of the pulmonary vasculature. ${ }^{2} \mathrm{~S} 1 \mathrm{Q} 3 \mathrm{~T} 3$ is also associated with the early affection of RV dysfunction. ${ }^{35}$ Presence of the S1Q3T3-pattern is suggestive of RV strain from acute PHT in the cases with acute PE. ${ }^{36}$ So, this pattern could be used as a predictor of RV dysfunction and as indirect markers for risk stratification in the cases of $\mathrm{APE}^{35}$ However, S1Q3T3 is an independent predictor of $\mathrm{PE}^{37,38} \mathrm{~S} 1 \mathrm{Q} 3 \mathrm{~T} 3$ pattern is suggesting RV overload. ${ }^{39}$ Daniel et al. proposed a 21-point ECG scale to evaluate the relationship between the severity of PHT and ECG in patients with APE. ${ }^{30,40}$ The presence of classic McGinn-White sign in the case of PTE signifies associated severity rather than a higher mortality rate. ${ }^{\mathbf{2 6 , 4 1 , 4 2}}$ Shopp et al reported that the S1Q3T3 sign in $16.6 \%$ of ECG findings that predicted hemodynamic collapse and death within 30 days of acute PE. ${ }^{\mathbf{3 6}}$ The presence of the RV strain pattern on the ECG is linked to an increased risk of all-cause death and clinical deterioration. ${ }^{43}$ Systematic review and meta-analysis demonstrate that following 6 findings in ECG will be suggesting RV strain due to acute PHT; (A). Sinus tachycardia. (B). The S1Q3T3-pattern, (C). Right bundle branch block (RBBB). (D). T-wave inversions in V2 and V3. (E). ST-elevation in the aVR lead. (F). Atrial fibrillation (AF). All the above signs are significantly associated with the probability of circulatory shock and death from APE. ${ }^{36}$ The combination of patient's symptoms with the ECG S1Q3T3 pattern is the way for suspected $\mathrm{APE}$ and therefore to request a ventilation and perfusion scan, which showed the low probability for $\mathrm{PE}^{5}$ Calvo-Romero1 et al. reported that the S1Q3T3-pattern is one of the main determinants of severity between the ECG abnormalities at the time of diagnosis of acute PE. ${ }^{12}$ Numerous clinical benefits of S1Q3T3pattern regards pulmonary embolism are listed (Table 2).

Table 2. List of clinical significance of S1Q3T3-pattern regards pulmonary embolism.

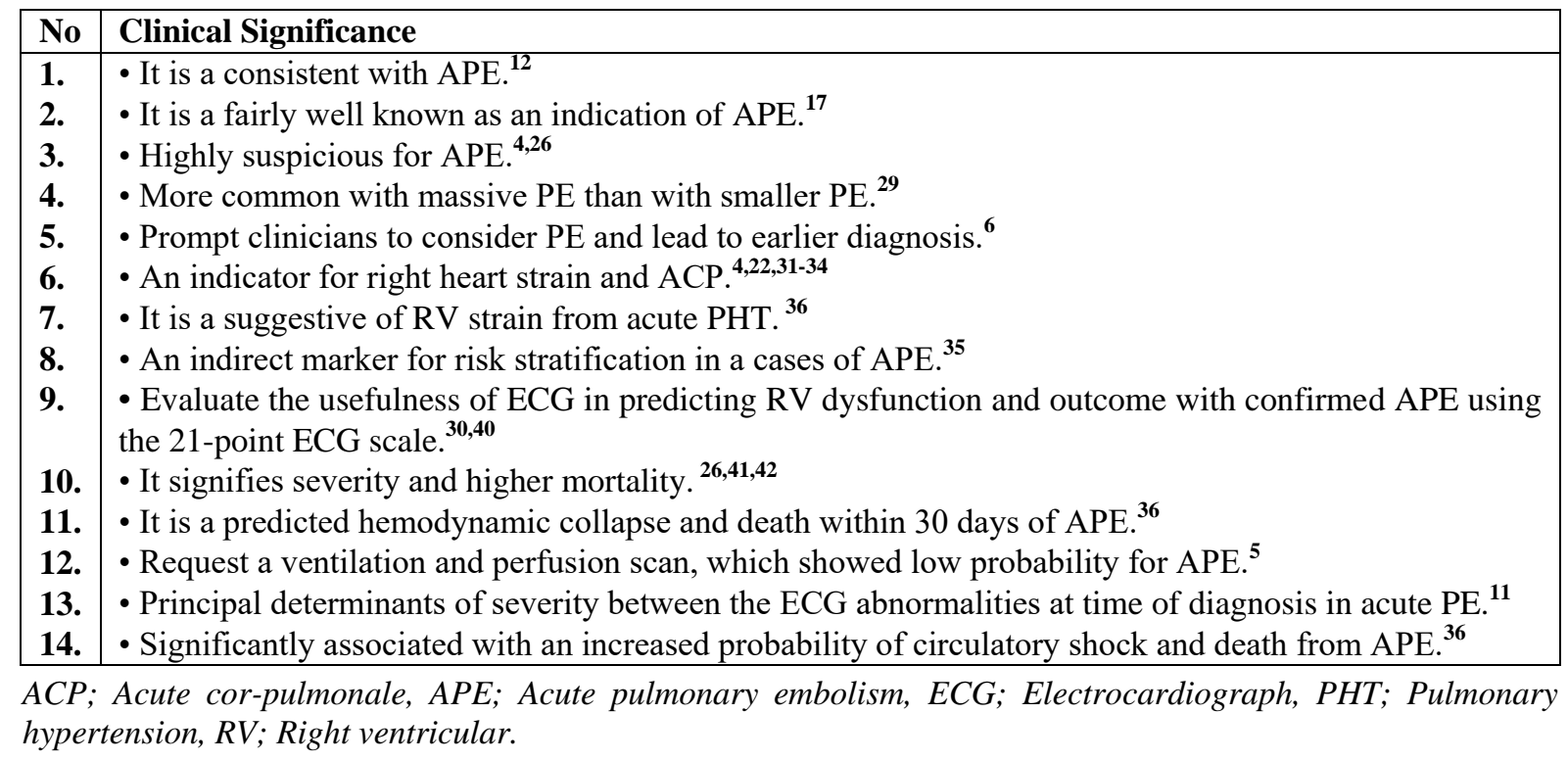

\section{CHILDREN}

Almost $15 \%$ of patients in cohort studies presented with shock or cardiac arrest had previous echoing reports of APE. ${ }^{44,45}$ About $33.3 \%$ of patients described as having either massive or submassive PE. ${ }^{\mathbf{4 4} 46}$ Evidence of the classic S1Q3T3 finding is only reported in $12 \%$ of acute thromboembolic PE in children. ${ }^{45}$

\section{ECG AND Pulmonary EMbOLISM}

The ECG may be helpful as a diagnostic tool for $\mathrm{PE}$, but it has limited value due to its lack of both sensitivity and specificity. ECG is an initial choice workup because the results are normal in only about $18-29 \%$ of all cases of PE $(6 \%$ massive and $23 \%$ submassive). ${ }^{\mathbf{3} 47}$ In fact, a large number of patients with PE will have no ECG abnormalities at all! ${ }^{17}$ The animals and 
McGinn-White Sign or S1Q3T3-Pattern in Pulmonary Embolism; Significance and Differential Diagnosis; Narrative Updating Review

humans studies have shown that approximately $50 \%$ of the occluded pulmonary arterial bed will be producing changes in the ECG. ${ }^{48}$ Electrocardiographic abnormalities are seen in $70 \%-80 \%$ of patients presented with APE. The common features including sinus tachycardia, RBBB, S1Q3T3 pattern, precordial non-specific ST-segment depression, and T-wave changes 47,49,50 will authorize the physician for further diagnostic testing and treating the suspected $\mathrm{PE}^{47}$ Although some ECG changes are more common in PE, the ECG alone is inadequate to accept or reject the diagnosis. ${ }^{3}$ Despite this sign has a low ECG sensitivity and specificity for diagnosing PE, but it can still direct clinicians. ${ }^{3,9}$ No characteristic ECG abnormality is definitively associated with PE. ${ }^{9}$ Sinha and associates $^{51}$ revealed that even though standard ECG findings have relatively low clinical use, they could indicating the pretest probability of PE before performing computed tomography pulmonary angiography (CTPA). The physician should be considered the probability of pulmonary embolism (76\%) if there is the presence of $\geq 3$ of the following abnormalities ${ }^{4,20}$ : (1) Incomplete or complete RBBB which was associated with ST-segment elevation and positive T-wave in lead V1; (2) S-waves in leads I and aVL of $>1.5 \mathrm{~mm}$; (3) a shift in the transition zone in the precordial leads to V5; (4) Q-waves in leads III and aVF, but not in lead II; (5) Right-axis deviation (RAD), with a frontal QRS-axis of $>90$ degrees, or an indeterminate axis; (6) A lowvoltage QRS-complex of $<5 \mathrm{~mm}$ in the limb leads; and (7) T-wave inversion in leads III and aVF or leads V1 to V4, which occurred more often in patients with symptoms for $>7$ days. Sinus tachycardia was the most common followed by ST-T changes in V1-V3 and S1Q3T3 in cases of PE. 'The combination of S1Q3T3 with a new $\mathrm{RBBB}$ seen in this case presentation is indicative of ACP, but in this particular clinical setting was highly suspicious for PE with RV strain. ${ }^{4}$ The other ECG abnormalities are suggestive for RV overload and evaluated concerning their impact on in-hospital mortality ${ }^{52}$ : (1) Sinus tachycardia or bradycardia. (2) Atrial arrhythmias. (3) Heart block; (4) Abnormal axis deviation; (5) Shifting in the transition zone $(\mathrm{R}=\mathrm{S})$ to V5 or further leftward; (6) Complete or incomplete RBBB; (7) Peripheral low voltage (in the limb leads); (8) Pseudo-infarction pattern (deep Q waves) in leads III and aVF; (9) ST-segment elevation $\geq$ $0.1 \mathrm{mV}$ over the right (V2-V3) or the left (V4V6) precordial leads; (10) ST-segment depression $\geq 0.05 \mathrm{mV}$ over the right or the left precordial leads; and (11) T-wave inversion over the right or the left precordial leads. $\mathrm{Chou}^{48}$ suggests that the following findings are typical: (1) an S1Q3 or S1Q3T3 pattern; (2) A RAD; (3) Transient complete or incomplete RBBB; (4) Twave inversion in the right precordial leads; and (5) sinus tachycardia. Other more rare findings are (a) left displacement of the transitional zone; (b) left axis; (c) QR in V1; (d) R. S in V1; (e) ST elevation in lead III.

\section{Pathogenesis of MCGinN-White Sign}

S1Q3T3-pattern is a consequence of volume and pressure overload in the RV. It may appear in other ACP-causing disorders. The $\mathrm{S}$-wave in lead I indicate the presence of RBBB. The Qwave with the $\mathrm{T}$-wave inversion in lead III points to RV strain. ${ }^{3}$ It was extrapolated that the S1Q3T3-pattern was a sign of RV change due to occlusion of the pulmonary vasculature. ${ }^{2}$ Moreover, ECG features with RV strain have been found to correlate with the degree of pulmonary artery obstruction due to PE, increased pressure, and wall tension on the $\mathrm{RV} .{ }^{43}$ The presence of the RV strain pattern on the ECG is correlating with an increased risk of all-cause death and clinical deterioration. ${ }^{43}$ In patients of RV dysfunction, T-wave inversion in leads V1-V3 has greater sensitivity and diagnostic accuracy if compared with the S1Q3T3 and RBBB features which have good specificity and moderate accuracy. ${ }^{43}$ The S1Q3T3-pattern is the direct result of right heart strain due to increased RV pressures (e.g., ACP). This will be parallel to meeting an increasing the resistance in the RV which it must pump against the strain will result. ${ }^{24,25}$ It was noted that with significant occlusion of the pulmonary artery, the RV and RA quickly dilate leading to ACP. When the right side of the heart dilates, it causes a rotation in the transverse level causing the RV to move anteriorly and the LV to move posteriorly. When this occurs changes in ECG occur, including the S1Q3T3pattern. ${ }^{1,53}$

\section{SENSITIVITY AND SPECIFICITY OF S1Q3T3 SIGN}

The S1Q3T3-pattern is a frequently faced pattern that makes its diagnostic value will debatable. ${ }^{54,55}$ Unfortunately, the S1Q3T3 sign was mistakenly by numerous clinicians as the pathognomonic ECG-pattern for APE over decades. ${ }^{\mathbf{1 8 2 1}}$ This classic sign is neither pathognomonic, sensitive, nor specific. ${ }^{56}$ It is not a certain pathognomonic of APE. ${ }^{18}$ While the 
McGinn-White Sign or S1Q3T3-Pattern in Pulmonary Embolism; Significance and Differential Diagnosis; Narrative Updating Review

S1Q3T3-pattern is frequently taught in medical sessions worldwide as the pathognomonic ECG pattern with APE. ${ }^{\mathbf{1 8}}$ However, The reported incidence in APE is quite highly variable with studies from $10-50 \%^{18,22}$ and in some studies is equally likely in patients without APE. ${ }^{\mathbf{1 8}}$ Regrettably, the McGinn-White sign is insensitive and non-specific for the diagnosis of APE. S1Q3T3-pattern had a sensitivity of 54\% and a specificity of $62 \%$ in pulmonary embolism. ${ }^{4,57}$ This is a very non-specific pattern seen in patients with right heart strain. ${ }^{9}$ Thus, the S1Q3T3-pattern supports a diagnosis of pulmonary embolism but does not confirm it. The S1Q3T3-pattern in the ECG is highly nonspecific for PE. However, it is equally likely to be found in patients without PE who were initially suspected to have PE. ${ }^{58}$

\section{Potentiation OF S1Q3T3-PATTERN}

The presence of sinus tachycardia along with Swave in the lead I, Q-wave, and inverted Twave in the lead III are commonly associated with acute massive PE causing ACP. ${ }^{6}$ The combination of S1Q3T3 with a new RBBB seen in this case presentation is indicative of ACP. These are highly suspicious of PE with RV strain. ${ }^{4}$ If the V1 and V2 leads are an inverted in conjunction with S1Q3T3 pattern, this is a very specific finding in APE. ${ }^{17} \mathrm{PR}$ displacement, late $\mathrm{R}$ in aVR, slurred $\mathrm{S}$ in $\mathrm{V} 1$ or V2, the S1Q3T3 pattern and $\mathrm{T}$-wave inversion in $\mathrm{V} 1$ or $\mathrm{V} 2$ are remarkably common in patients with confirmed PE. ${ }^{6,27}$ Nazeyrollas et al.$^{59}$ found that the $S$-wave in I and Q-wave in III is significantly more common among those with confirmed PE.

\section{TRANSIENT S1Q3T3 AND REVERSIBILITY OF SIGN}

Reported cases of reversible S1Q3T3-pattern were described with pulmonary embolism ${ }^{2}$, pneumothorax ${ }^{60}$, and in the pregnant asthmatic exacerbations. ${ }^{5}$ Spontaneous resolving is meaning that the S1Q3T3 pattern in subsequent electrocardiogram findings of a patient with $\mathrm{PE}$ is not a permanent sign. It is frequently transient, short-lived, and resolving within 14 days after onset of the disease. ${ }^{21,61}$ The S1Q3T3- pattern is commonly reversed into a normal state after the treatment for PE. $\mathbf{1 , 5 7 , 6 2}$

\section{DIFFERENTIAL DIAGNOSIS OF S1Q3T3 PATTERN}

However, this pattern is likely to be seen more often in pulmonary and non-pulmonary embolism patients. (Table 1) The ECG changes of S1Q3T3 were present in $10 \%$ of those with non-embolic pulmonary embolism. ${ }^{5}$ All causes of ACP, including PE, can result in the S1Q3T3

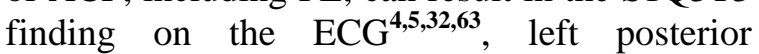
fascicular block (LPFB) ${ }^{\mathbf{5}, 31}$, aortic intramural hematoma with extension to pulmonary artery ${ }^{5,64}$, previous inferior myocardial infarction (IMI) ${ }^{65}$, acute bronchospasm (BA) ${ }^{\mathbf{5 , 3 2 , 6 3}}$ in pregnant women ${ }^{5}$, right side pneumothorax ${ }^{5,14,32,60 \text {, }}$ 63, lobar pneumonia ${ }^{14,66,67}$, exacerbation of obstructive airway disease ${ }^{68}$, atelectasis, recent pneumonectomy ${ }^{69}$, or upper airway obstruction ${ }^{4,5}$, pulmonary hypertension ${ }^{\mathbf{1 0}, \mathbf{0}}$, obstructive sleep apnea (OSA $)^{\mathbf{4 , 5}}$, acute respiratory distress syndrome (ARDS) $)^{4,5}$, pulmonary hemorrhage ${ }^{4,5}$, neoplastic disease ${ }^{14}$, and other acute pulmonary

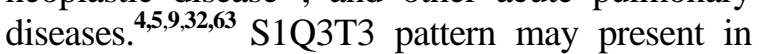
Cor-Triatriatum. ${ }^{71}$

Although the S1Q3T3 sign can be a helpful clue in the diagnosis of $\mathrm{PE}$, this sign is rarely present in patients with ventilation-perfusion (VQ) mismatch like-pneumonia. ${ }^{14}$ This pattern reflects a RAD state so, the RV appears projected more anteriorly and to the right of the LV. ${ }^{72}$ This sign is poorly specific because it sometimes is seen in a normal state, in a slim patient, or in the various diseases associated with RV overload (PHT, COPD, and emphysema) or RBBB. ${ }^{72}$ Its diagnostic value increases with the presence of characteristic clinical signs or other evocative electrical signs and when it appears or accentuates suddenly and disappears on subsequent tracings. This sign is most often short-lived, appears early, and disappears within a few days. ${ }^{72}$ The S1Q3T3 sign may be acutely present in $12 \%$ with; tricuspid regurgitation (area $>\mathrm{m} / \mathrm{sec}$ ), septal flattening, and RV dilation. ${ }^{44}$ There is broad-spectrum etiological differentiation for the S1Q3T3-pattern (Table 3).

Table3. Etiological summary of S1Q3T3-pattern

\begin{tabular}{|c|c|c|}
\hline Respiratory & Cardiovascular & Others \\
\hline $\begin{array}{l}\text { - Pneumothorax } \mathbf{5 , 1 4 , 3 2 , 6 0 , 6 3} \\
\text { - Acute bronchospasm or bronchial } \\
\text { asthma }{ }^{\mathbf{5 , 3 2 , 6 3}} \\
\text { - Exacerbation of obstructive airway } \\
\text { disease }{ }^{68,72} \\
\text { - Severe pneumonia } \mathbf{1 4 , 6 6 , 6 7}\end{array}$ & $\begin{array}{l}\text { - Pulmonary embolism } \\
\text { - } \text { LPFB }^{5,31} \\
\text { - Old IMI } \\
\text { - } \text { Cor-Triatriatum }^{\mathbf{7 1}} \\
\text { - } \text { RBBB }^{\mathbf{7 2}} \\
\text { - Tricuspid regurgitation }\end{array}$ & $\begin{array}{l}\text { - Normal variant } \\
(15 \%)^{\mathbf{7 2}} \\
\text { - Neoplasms }{ }^{14} \\
\text { - Slim patient }\end{array}$ \\
\hline
\end{tabular}


McGinn-White Sign or S1Q3T3-Pattern in Pulmonary Embolism; Significance and Differential Diagnosis; Narrative Updating Review

\begin{tabular}{|c|c|}
\hline $\begin{array}{l}\text { - } \text { ARDS }^{\mathbf{4 , 5}} \\
\text { - Pulmonary hemorrhage } \\
\text { - Atelectasis } \\
\text { - Upper airway obstruction } \\
\text { - }{ }^{\mathbf{4 , 5}} \\
\text { - Recent pneumonectomy } \\
\mathbf{6 9}\end{array}$ & $\begin{array}{l}\text { - RV dilation }{ }^{44} \\
\text { - Septal flattening } \\
\text { - Aortic intramural hematoma with } \\
\text { extension to pulmonary artery } 5,64\end{array}$ \\
\hline
\end{tabular}

ARDS; Acute respiratory distress syndrome, IMI; Inferior myocardial infarction, LPFB; Left posterior fascicular block, OSA; Obstructive sleep apnea, RV; Right ventricular

\section{S1Q3T3 PATTERN ALARMS}

There are serious alarms for acute pulmonary embolism. Massive pulmonary embolism ${ }^{5,6,8,9}$, acute cor-pulmonal ${ }^{\mathbf{1 , 5 , 6 , 8 , 9}}$, cardiogenic shock $^{\mathbf{8 , 9},}$ cardiogenic pulmonary edema $^{\mathbf{8}}$, and sudden death $^{\mathbf{8}, 9}$ are common associations and serious sequels for S1Q3T3-pattern. (Figure 1)

\section{Cardiogenic pulmonary edema}

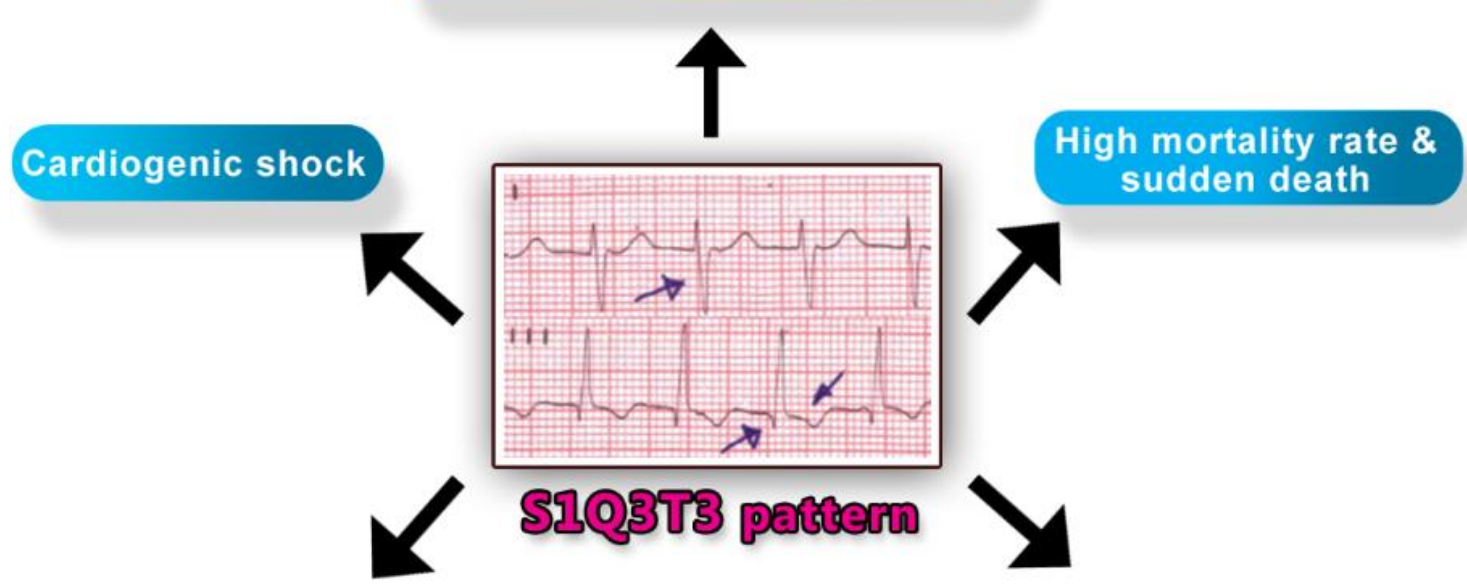

Acute Cor-pulmonal

Massive pulmonary embolism

Figure1. S1Q3T3 pattern is a signal for the outcome.

\section{CONClusions}

The author had concluded that the McGinnWhite sign or S1Q3T3-pattern not a pathognomonic sign for acute pulmonary embolism. But it is a guide for pulmonary embolism. S1Q3T3 sign can be found in other states like acute cor-pulmonale and right heart strain. The clinical data is the most important factor for the physician in the directory of the outcome for S1Q3T3-pattern.

\section{ACKNOWLEDGMENT}

I wish to thank Dr. Ameer Mekkawy; M.sc. for technical support.

\section{REFERENCE}

[1] McGinn S, White Paul. Acute cor pulmonale resulting from pulmonary embolism: its clinical recognition. JAMA. 1935 April, 27;104 (17) :14 73-1480.DOI:10.1001/jama.027601700110041 935.

[2] Cygan LD, Weizberg M, Hahn B. Spontaneous, resolving S1Q3T3 in pulmonary embolism: A case report and literature review on prognostic value of electrocardiography score for pulmonary embolism. Int Emerg Nurs. 2016 Sep;28:46-9. PMID:27222012 DOI:10.1016/j.ienj.2016.04.003.

[3] Raghav KP, Makkuni P, Figueredo VM. A review of electrocardiography in pulmonary embolism: recognizing pulmonary embolus masquerading as ST-elevation myocardial infarction. Rev Cardiovasc Med. 2011; 12(3): 157-63. PMID:22145193

[4] Báez A, Goyal D. Acute cor pulmonale from massive bilateral pulmonary emboli. The Internet Journal of Emergency Medicine. 2005;3(1):1-3. Available from: http:// ispub. com/IJEM/3/1/6041

[5] Arshad H, Khan R R, Khaja M. Case report of S1Q3T3 electrocardiographic abnormality in a pregnant asthmatic patient. Am J Case Rep. 2017;18:110-113. DOI:10.12659/AJCR.901661 PMID: 28144025 PMCID: PMC5297401

[6] Shahani L1. S1Q3T3 pattern leading to early diagnosis of pulmonary embolism. BMJ Case Rep. 2012 Jul 9;2012. pii: bcr2012006569. PMID:22778481 PMCID:PMC4544359 DOI: 10.1136/bcr-2012-006569 
McGinn-White Sign or S1Q3T3-Pattern in Pulmonary Embolism; Significance and Differential Diagnosis; Narrative Updating Review

[7] Rawal G, Yadav S, Kumar R, and Sujana R. ECG as diagnostic tool for pulmonary embolism: A case report. Indian Journal of Immunology and Respiratory Medicine, 2017 Oct-Dec;2(4): 111-112. DOI: 10.18231/2456012X.2017.0025

[8] Doralisa Morrone and Vincenzo Morrone. Acute Pulmonary Embolism: Focus on the Clinical Picture. Korean Circ J. 2018 May; 48(5): 365-381. DOI:10.4070/kcj.2017.0314 PMCID: PMC5940642 PMID: 29737640

[9] Chandra Mani Adhikari, K.C. Bishal, and Sobita Khadka. Clinical profile, management and outcome of pulmonary embolism in Shahid Gangalal National Heart Centre, Kathmandu, Nepal. Egypt Heart J. 2018 Mar;70(1):41-43. PMID: 29622996. DOI:10. 1016/j.ehj. 2017.06. 001 PMCID: PMC5883507

[10] Jaff MR, McMurtry MS, Archer SL, et al. Management of massive and submassive pulmonary embolism, iliofemoral deep vein thrombosis, and chronic thromboembolic pulmonary hypertension: A scientific statement from the American Heart Association. Circulation. 2011 Apr 26;123(16):1788-830. PMID:21422387DOI:10.1161/CIR.0b013e318 $214914 \mathrm{f}$

[11] Cameron P, Kelly AM, Brown A, Mark L. Textbook of Adult Emergency Medicine. Elsevier Ltd. $4^{\text {th }}$ ed. 2015, pp 247. ISBN 978-07020-5335-1

[12] Calvo-Romero1 JM, Lima-Rodriguez LM. Electrocardiographic abnormalities in acute pulmonary embolism. Eur J Gen Med. 2005; 2(4):150-152. DOI: https://doi.org/ 10.29333/ ejgm/82332

[13] William JB and Jonathon DT. Critical Decisions in Emergency and Acute Care Electrocardiography. [ [ ${ }^{\text {st }}$ ed]. 2009;54-55. Blackwell Publishing Ltd. ISBN: 978-1-40515906-7.

[14] Ahmad Q. Hasan and Al-Khazraji A. What We Know About S1Q3T3 Electrocardiographic Findings: A Case Report and Literature Review. JMSCR. 2016 July;4(7):11633-11635. DOI:http://dx.doi.org/10.18535/jmscr/v4i7.74

[15] Sokolow M, Katz LN, and Muscovitz AN. The electrocardiogram in acute pulmonary embolism. Am Heart J. 1940 Jan;19:166-184. Available from: https://doi.org/10.1016/S00028703(40)90343-X (Accessed 1940, Feb).

[16] Richard D. Sautter. The UrokinasePulmonary Embolism Trial. JAMA. 1974; 227 (10):1168-1169. DOI:10.1001/ jama.1974. 032 30230044026

[17] Owen Wood. A Few Words About S1Q3T3. Available on :https://www.ditchdocem. com/ 2017 /02/10/about-s1q3t3/ (Accessed in: Posted on February 10, 2017)
[18] Todd K, Simpson CS, Redfearn DP, Abdollah H, Baranchuk A. ECG For The Diagnosis of Pulmonary Embolism When Conventional Imaging Cannot Be Utilized: A Case Report And Review Of The Literature Indian Pacing and Electrophysiology Journal. 2009;9(5):268-275.

[19] Grant OA, Ballantyne B, and Haddara W. Unique ECG Findings in Acute Pulmonary Embolism: STE with Reciprocal Changes and Pathologic Q Wave. Case Rep Crit Care. 2018 Apr 3;2018:7865894:13 .DOI:10.1155/2018/ 7865894.

[20] Sreeram N, Cheriex EC, Smeets JL, Gorgels AP, Wellens HJ. Value of the 12-lead electrocardiogram at hospital admission in the diagnosis of pulmonary embolism. Am J Cardiol. 1994 Feb 1;73(4):298-303. PMID:82 96763

[21] Ullman E, Brady WJ, Perron AD, Chan T, Mattu A. Electrocardiographic manifestations of pulmonary embolism. Am J Emerg Med. 2001;19:514-9. DOI:1 0.1053/ajem.2001.27172

[22] Rodger M, Makropoulos D, Turek M, Quevillon J, Raymond F, Rasuli P, Wells PS. Diagnostic value of the electrocardiogram in suspected pulmonary embolism. Am J Cardiol. 2000 Oct 1;86(7):807-9, A10. PMID:11018210

[23] Chan TC1, Vilke GM, Pollack M, Brady WJ. Electrocardiographic manifestations: pulmonary embolism. J Emerg Med. 2001 Oct; 21(3):263-70. PMID:11604281

[24] Wood O. A Few Words About S1Q3T3. Available from https://www. ditchdocem. com/2017/02/10/about-s1q3t3/ (Accessed 2018, October 30).

[25] Ouellette DR and Harrington A. Pulmonary Embolism. Available from: https://emedicine. medscape.com/article/300901-overview (Accessed 2018, September 17).

[26] Yu H-H, Jeng J-R. Pulseless electrical activity in acute massive pulmonary embolism during thrombolytic therapy. Ci Ji Yi Xue Za Zhi. 2017 Jan-Mar; 29(1): 50-54.DOI: 10.4103/ tcmj. tcmj_7_17 PMCID: PMC5509188 PMID: 287 57765

[27] Petruzzelli S, Palla A, Pieraccini F, et al. Routine electrocardiography in screening for pulmonary embolism. Respiration. 1986; 50(4): 233-43. PMID:3823634 DOI:10.1159/000194 933

[28] Francis J. S1Q3T3 pattern on ECG in pulmonary embolism. Available from: https:// johnsonfrancis.org/professional/s1q3t3-patternon-ecg/ (Accessed June 30, 2012)

[29] Codolosa JN, Balestra R, David M, Eiger G, and Jegel KM. A 59-Year-Old Man With Shortness of Breath After Colectomy. 
McGinn-White Sign or S1Q3T3-Pattern in Pulmonary Embolism; Significance and Differential Diagnosis; Narrative Updating Review

Availablefrom: https://reference.medscape. com/viewarticle/741905_4 (Accessed 2018, Aug 27).

[30] Kostrubiec M, Hrynkiewicz A, Włoszek JP, et al. Is it possible to use standard electrocardiography for risk assessment of patients with pulmonary embolism? Kardiol Pol. 2009 Jul 1; 67(7):744-750. PMID: 196 49996

[31] Cheng ASH and Kyrle AM. Instructive ECG series in massive bilateral pulmonary embolism. Heart. 2005;91:860-862. DOI: 10. 1136/hrt.2004.049114

[32] Ali OM, Masood AM, Siddiqui F. Bedside cardiac testing in acute cor pulmonale. BMJ Case Rep. 2014 Jun 17; 2014: pii: bcr2013200940 PMID:24939650 PMCID: PMC4069795 DOI:10.1136/bcr-2013-200940

[33] EKEN J, Shian B. Chest Pain with Diffuse TWave Inversion; Photo Quiz. Am Fam Physician. 2014 Aug 15;90 (4):257-8. PMID: 25251001

[34] Cana MM, Can E, Turan B, and Kaymaz C. Atipic electrocardiographic manifestation of pulmonary Embolism; Letter to the Editor. Resuscitation. 2010;81(12) 1738-1739. Available from: https://doi.org/ 10.1016/j resuscitation.2010.07.023 (Accessed 2010 December)

[35] Devesa A, Rivero AL, Romero-Daza AM, et al. Electrocardiographic Changes as a Predictor of Right Ventricle Dysfunction in Acute Pulmonary Embolism. Circulation. 2017 Nov 14 ;136(Supp1):A18323. Available from: https://www.ahajournals.org/doi/abs/10.1161/ci rc.136.suppl_1.18323 (Accessed2017, Nov 14).

[36] Shopp JD, Stewart LK, Emmett TW Kline JA. Findings From 12-lead Electrocardiography That Predict Circulatory Shock From Pulmonary Embolism: Systematic Review and Meta-analysis. Acad Emerg Med. 2015 Oct;22(10):1127-37. PMID:26394330 PMCID:PMC5306533

DOI:10.1111/acem.12769

[37] Rodrigues B, Correia H, Figueiredo A, Delgado A, et al. Clot burden score in the evaluation of right ventricular dysfunction in acute pulmonary embolism: Quantifying the cause and clarifying the consequences. Rev Port Cardiol. 2012;31(11):687---695.

[38] Dr. Smith. Acute Respiratory Distress, Hypoxia, and a Large Right Ventricle on Bedside Ultrasound. Available from: http:// hqmeded-ecg.blogspot.com/2016/05/ (Accessed, 2016, May 27)

[39] Guenther NL, Nunes NGSV, de Souza PV, ande Souza RV. Use of Thrombolysis in PE Said to be of no High-Risk, which Presents Acute Cor Pulmonale. International Journal of
Cardiovascular Sciences. 2017;30(5):452-458. http://dx.doi.org/10.5935/2359-4802.20170054

[40] Daniel KR, Courtney DM, Kline JA. Assessment of cardiac stress from massive pulmonary embolism with 12-lead ECG. Chest. 2001 Aug;120(2):474-81. PMID:11502646

[41] Nampoothiri RV, Lakshman A, Bhalla A, Varma S. ECG In Evaluation for Pulmonary Thromboembolism. Occam's Razor or Hickam's Dictum? J Clin Diagn Res. 2016;10(5):OJ01. Published online 2016 May 1. PMCID: PMC4948468 PMID: 27437292 DOI: $10.7860 / J C D R / 2016 / 16877.7872$

[42] Kukla P, Długopolski R, Krupa E, Furtak R, Wrabec K, Szelemej R, et al. The value of ECG parameters in estimating myocardial injury and establishing prognosis in patients with acute pulmonary embolism. Kardiol Pol. 2011;69(9):933-38. PMID:21928203

[43] Boey E, Teo SG, Poh KK. Electrocardiographic findings in pulmonary embolism. Singapore Med J. 2015 Oct;56(10):533-7. PMID:26512143 PMCID: PMC4613926 DOI:10. 11622 /smedj. 2015147

[44] Pelland-Marcotte MC, Tucker C, Klaassen A, et al. Outcomes and risk factors of massive and submassive pulmonary embolism in children: a retrospective cohort study. Lancet Haematol. 2019 Feb 13; 1-10. DOI: 10.1016/S2352-3026(18)30224-2 Published Online February 13, 2019.

[45] Hancock HS, Wang M, Gist KM, et al. Cardiac findings and longterm thromboembolic outcomes following pulmonary embolism in children: a combined retrospective-prospective inception cohort study. Cardiol Young. 2013 Jun;23(3):344-52. PMID:23088931 DOI: 10. 1017/S1047951112001126

[46] Kucher N, Rossi E, De Rosa M, Goldhaber SZ. Massive pulmonary embolism. Circulation. 2006 Jan 31;113(4):577-82. PMID:16432055 DOI:10.1161/CIRCULATIONAHA.105.592592

[47] Senthilkumaran S, Jena NN, Balamurugan N, Benita F, Thirumalai kolundusu bramanian $\mathbf{P}$. The electrocardiogram in pulmonary embolus: Diagnostic applications. Am J Emerg Med. 2019 Jan;37(1):165-166. DO I:10.1016/j.ajem.2018.05.045PMID:30509 376

[48] Chou T. Electrocardiography in clinical practice. [ $6^{\text {th }}$ ed]. Elsevier Inc.2008, pp 306307. ISBN: 978-1-4160-3774-3.

[49] Hesham R O. ST-segment elevation in V1-V4 in acute pulmonary embolism: a case presentation and review of literature. Eur Heart J Acute Cardiovasc Care. 2016 Dec;5(8):579586. PMID:26373811 DOI:10.1177/ 204887 2615604273

[50] Mistry A, Natarajan N, Hussain S, Vali Z. Unusual presentation of acute pulmonary 
McGinn-White Sign or S1Q3T3-Pattern in Pulmonary Embolism; Significance and Differential Diagnosis; Narrative Updating Review

embolus presenting with inferior ST elevation. BMJ Case Rep. 2018 Jul 30;2018. PMID: 30065059 DOI:10.1136/bcr-2018-226063

[51] Sinha N, Yalamanchili K, Sukhija R, et al. Role of the 12-lead electrocardiogram in diagnosing pulmonary embolism. Cardiol Rev. 2005 Jan-Feb;13(1):46-9. PMID:15596029 DOI:10.1097/01.crd.0000134647.55135.4a

[52] Geibel A, Zehender M, Kasper W, Olschewski M. Klima C, and Konstantinides S V. Prognostic value of the ECG on admission in patients with acute major pulmonary embolism. Eur Respir J. 2005; 25:843-848. DOI: 10.1183/09031936.05.00119704

[53] Mercer M and Patel K. Electrocardiographic Findings in Pulmonary Emboli. Curr Emerg Hosp Med Rep. 2015;3:109-112. DOI 10.1007/ s40138-015-0075-9

[54] Icli A, Kayrak M, Akilli H, et al. Prognostic value of Tpeak-Tend interval in patients with acute pulmonary embolism. BMC Cardiovascular Disorders. 2015;15(99):1-8. DOI 10.1186/s12872-015-0091-4

[55] Stein PD, Dalen JE, McIntyre KM, et al. The electrocardiogram in acute pulmonary embolism. Prog Cardiovasc Dis. 1975 JanFeb;17(4):247-57. PMID:123074

[56] Wagner MJ, Promes SB. Pulmonary Embolism. Last Minute Emergency Medicine. McGraw-Hill Companies, Inc.2007;17:424. DOI:10.1036/0071459626

[57] Ferrari E, Imbert A, Chevalier T, et al. The ECG in pulmonary embolism. Predictive value of negative $\mathrm{T}$ waves in precordial leads- 80 case reports. Chest. 1997 Mar;111(3):537-43. PMID: 9118684

[58] Rodger M, Makropoulos D, Turek M, Quevillon J, et al. Diagnostic value of the electrocardiogram in suspected pulmonary embolism. Am J Cardiol. 2000 Oct 1;86(7):807-9, A10. PMID:11018210

[59] Nazeyrollas P, Metz D, Jolly D, et al. Use of transthoracic Doppler echocardiography combined with clinical and electrocardiographic data to predict acute pulmonary embolism. Eur Heart J. 1996 May; 17(5):779-86. PMID:8737110

[60] Goddard R, Scofield RH. Right pneumothorax with the S1Q3T3 electrocardiogram pattern usually associated with pulmonary embolus. Am J EmergMed. 1997 May;15:310-312. PMID: 9148995.

[61] Nielsen TT, Lund O, Rønne K, Schifter S. Changing electrocardiographic findings in pulmonary embolism in relation to vascular obstruction. Cardiology. 1989;76(4):274-284. PMID:2805014DOI:10.1159/000174504

[62] Durant TM, Ginsburg IVY, Roesler H,et al. Transient bundle branch block and other electrocardiographic changes in pulmonary embolism. Am Heart J. 1939 April;17(4):42330. Available from: https://doi.org/ 10. 1016/ S0002-8703(39)90592-2 (Accessed 1939 April)

[63] Levis JT. ECG Diagnosis: Pulmonary Embolism. Perm J. 2011 Fall;15(4):75. PMID:22319421 PMCID:PMC3267566

[64] Shiau EL, Wu FZ, Huang YL, Wu MT. Aortic intramural hematoma with pulmonary artery extension mimics pulmonary embolism. Am J Emerg Med. 2013 Oct;31(10):1538.e3-4. PMID:23790481 DOI:10. 1016/j.ajem.2013. 05.036

[65] Obiagwu C, Jinu John J , Mastrine L, Borgen E, and Shani J. Acute Pulmonary Embolism Masquerading as Acute Inferior Myocardial Infarction. Journal of Medical Cases. 2014;5(2):73-75 DOI: https://doi.org/ 10.14740/jmc1584e

[66] Stein PD, Matta F, Ekkah M, et al. Electrocardiogram in pneumonia. Am $J$ Cardiol. 2012 Dec 15;110(12):1836-40. PMID: 23000104 DOI:10.1016/j.amjcard.2012.08.019

[67] ThomsonKJ, Rustein DD, Tolmach DM, Walker WH. Electrocardiographic studies during and after pneumococcus pneumonia. Am Heart J. 1946 May;31(5):565-79. PMID: 20 981943

[68] Thomson D, Kourounis G, Trenear R., Messow CM., Hrobar P, Mackay A, and Isles C. ECG in suspected pulmonary embolism. Postgraduate Medical Journal. 2019 Jan 29;1-25. DOI:10.1136/postgradmedj-2018136178 PMID:30665906

[69] Manjunath B V, Sahoo B, Thakre G, Gudage N. Case of acute pulmonary embolism in post pneumonectomy-a rare clinical presentation and management. Int J Res Med Sci. 2017 Aug;5(8):3745-3747. DOI: http:// dx.doi.org/10.18203/2320-6012.ijrms20173599

[70] Marchick MR, Courtney DM, Kabrhel C, et al. 12-lead ECG findings of pulmonary hypertension occur more frequently in emergency department patients with pulmonary embolism than in patients without pulmonary embolism. Ann Emerg Med. 2010 Apr;55 (4):331-5. PMID:19766353 DOI:10.1016/ j.annemergmed. 2009.07.025

[71] Reese DB. Cor Triatriatum. $N$ Engl J Med. 2004;350:1989.DOI:10.1056/NEJMicm990 415

[72] Cardiocases. Pulmonary embolism and S1Q3 pattern. Available from: https://www. cardiocases. com/en/ecg/traces/chest-painpulmonary-embolism/pulmonary-embolismand-s1q3-pattern

[73] Cutforth RH, Oram S. The electrocardiogram in pulmonary embolism. Br Heart J. 1958 Jan;20(1):41-60. PMID:13499769 PMCID: PMC492785 DOI:10.1136/hrt.20.1.41. 
McGinn-White Sign or S1Q3T3-Pattern in Pulmonary Embolism; Significance and Differential Diagnosis; Narrative Updating Review

[74] Jimenez D. ECG for risk stratification in patients with pulmonary embolism; Letter to Editor. Chest. 2003; 123: 1947-1952. DOI: 10. 1183/09031936.05.00054805

[75] Chua JC and Choa R. Clinical Outcomes and Electrocardiographic Score in Patients with Clinical Probability of Pulmonary Thromboembolism. Phil Heart Center J. 2013; 17(1):17-27. Available from: https:// www.phc.gov.ph/about-phc/journals/pdf/janjune2013/Clinical\%20Outcomes\%20and\% 20Electro cardiographic\%20Score.pdf (Accessed 2013 Jan-June)

[76] Lenègre J, Gerbaux A, Gay J. Electrocardiograms in pulmonary embolism [in French]. Bull Physiopathol Respir (Nancy). 1970 Jan-Mar;6(1):211-50. PMID:5521984

Citation: Yasser Mohammed Hassanain Elsayed, "McGinn-White Sign or S1Q3T3-Pattern in Pulmonary Embolism; Significance and Differential Diagnosis; Narrative Updating Review”, International Journal of Research Studies in Medical and Health Sciences. 2020; 5(11): 15-24.

Copyright: (c) 2020 Yasser Mohammed Hassanain Elsayed, This is an open-access article distributed under the terms of the Creative Commons Attribution License, which permits unrestricted use, distribution, and reproduction in any medium, provided the original author and source are credited. 